\title{
Designing the Self-Management Space of a New Smart Learning Management System
}

\author{
https://doi.org/10.3991/ijac.v13i4.15363 \\ Mohammed Ouadoud( $(\square)$ \\ Abdelmalek Essaadi University, Tetouan, Morocco \\ mohammed. ouadoudegmail.com \\ Nouha Rida \\ Mohammed V University, Rabat, Morocco \\ Tarik Chafiq \\ University Hassan II, Casablanca, Morocco
}

\begin{abstract}
This work is mainly based on designing an IMS-LD model for self-management space for a new LMS. Our work is first to think about the conditions for creating a real LMS between learners and teachers. We try to adapt the IMS-LD model with a self-management model based on the hybridization between four learning theories as to the basis for teaching this LMS, namely traditional pedagogy, behaviorism, cognitivism, and social constructivism. These pedagogies have already proven themselves, mainly in classroom learning situations.
\end{abstract}

Keywords - LMS, learning theories, conceptual model, the modeling of LMS, self-management model, self-management meta-model

\section{Introduction}

We present an easy self-management model of LMS to create and administer the educational content online. Therefore, it is necessary to find a method to model all LMS types. To model the self-management space of the LMS, we relied on the IMS$\mathrm{LD}^{1}$ specification and on the hybridization of four learning theories deemed to be the most relevant for our modeling, namely traditional pedagogy, behaviorism, cognitivism, and social constructivism. Then, these learning theories which have inspired for a long time the design of computer applications are combined and put into perspective with several emergent pedagogical functionalities to build original modeling for our self-management space of LMS.

${ }^{1}$ IMS-LD: Instructional Management Systems-Learning Design. Available at https://www.imsglobal.org/learningdesign 
The IMS-LD specification or instructional design engineering uses pedagogical concepts, allowing to model learning units. IMS-LD takes into account a wide variety of teaching models; therein lies its flexibility. A course plan extract of a general or specific database can be modeled with IMS-LD through the description of the different roles, activities, environments, methods ${ }^{2}$, properties, conditions, and notifications. It is used to transform the course plans into formal learning units (UOL) that can be performed with an IMS-LD editor based on an engine such as Copper core [18]. These executable units can be designed from the beginning using an editor such as Reload [19].

Several models of LMSs have been developed previously [13, 14, 15, 16, 17], but they have been abandoned because LMSs' life cycle is changing apace. Therefore, we have conducted a comparative and analytic study on free e-learning platforms based on an approach of evaluating the e-learning platforms' quality [1, 2, 3, 22]. Based on these various research works, which seemed to us incomplete, we proposed a modeling portrait of designing an IMS-LD self-management model for the new LMS platform. This latter is anthropocentric and relies on a learning conception that is located at the intersection of the most used learning theory.

To concretize our modeling work, we present, in section 3, the different theories of learning used for the modeling of this space, namely the traditional pedagogy, behaviorism, cognitivism, and social constructivism. We also present, in section 4, the online learning specification: IMS-LD and Atlas Language Transformation. Thus, in section 5, we try to adapt the proposed meta-model of the self-management space to the equivalent IMS-LD model. Finally, we present in section 6, the use case diagram of the self-management space. Thus, we adapt the class diagram model of the selfmanagement space to the equivalent IMS-LD model.

\section{$2 \quad$ LMS and Activity Spaces}

The learning management system consists of different activity spaces for activities of teaching and learning [30,31, 24]. Each model represents a space. In these spaces, both teachers and learners can have:

- Disciplinary information space

- Communication space

- Collaboration space

- Sharing space

- Evaluation space

- Production space

- Self-management space

- Assistance space

\footnotetext{
${ }^{2}$ The word "method" used by IMS-LD means the unfolding of the scenario.
} 


\section{Self-Management Space and the Underlying Learning Theories}

Although there is considerable potential in the construction of knowledge and competence development, the LMS can generate a real pedagogical success only if their use relies on solid and proven learning theories [25].

In the next part, we will evoke the transposition of the use of four learning theories in the design and development of the self-management space of LMS. For that purpose, we will do the correspondence between the tools available in LMS and the learning theories to which they refer. As the latter part will show, the hybridization of these learning theories that we have judged more important and relevant to our modeling work can only be a source of enrichment to improve the quality of online learning.

\subsection{Self-management space and the traditional pedagogy}

The conception of learning as supported by traditional pedagogy is essentially relying on a direct and systematic mode of transmission. Indeed, we put forward the authoritarian role of the teacher who must deliver fixed and unchanging knowledge, evaluate and involve learners by following the different stages of a pre-established scenario. From this perspective, learners are only passive recipients of the information who respond ideally to external factors provided by their teacher in advance in a particular environment. In this way, they develop their knowledge. Among the main ideas that are associated with the traditional pedagogy [35], we mention:

- Lecture-based teaching: this idea generally refers to the teaching-centered pedagogy in which the teacher is the main provider of subject content to learners. The acquisition of knowledge is assessed through various operations of reproduction such as recitation, examination, and practical exercises. Only the teacher has overall authority over learners who must follow his/her instructions and show goodwill to construct their knowledge more effectively.

- The idea of transmission and reception: we consider that the teacher delivers knowledge in ways that are clear, concise, and transparent and the learner receives it without any difficulty of memorization, understanding, and reproduction. Trial and error learning seems not to have its place in that perspective. The learner must listen, deploy efforts to study well, and recite per the teacher's expectations. The pedagogical relation is ideal from the teacher's point of view, the learner's spirit, and the object of transmission.

- Individualism: the learner is a part of a group but still works individually. No exchange between learners is allowed. This implies the absence of debate, dialogue, and communication. Everything is centralized around and by the teacher. No cognitive and social dimension exists in the learning process.

- The sanction: the role of the teacher is to identify errors. Learners are classified to generate a spirit of competition between them. Those who fail to learn are those who commit one or many errors. Making errors is not considered as a necessary 
step for learning but it is seen as being the fault of the learner who has not shown goodwill to learn.

These main ideas from the traditional pedagogy have had an impact on the design and development of LMS, which focus on learning by the reception. Indeed, this kind of software integrates different spaces to allow teachers to organize, structuring, exposing their knowledge, and particularly assessing the learning progress. Thus, a central place is given to teachers who do have the necessary tools to deliver knowledge and engage learners in the proposed learning activities of reproduction, consultation, and execution.

In general, we think that the contribution of the traditional pedagogy is so valuable to the extent that it allows teachers to facilitate and assist learners by putting at their disposal well-structured information based on over-prescriptive scenarios. However, traditional pedagogy has its limits that rely very much on the fact that learners who are considered as the main actors in the teaching-learning process are widely neglected. Their needs are not taken into consideration and they are only seen as passive receivers of knowledge.

\subsection{Self-management space and the behaviorist}

Behaviorism is a learning theory concerned with the study of human observable behavior without recourse to inner mental states [36]. It is built on the assumption that the brain is only a black box that no one can access.

The term "behaviorism" appeared at the beginning of the 20th century in parallel with the works of the American psychologist John Watson. The latter is considered the pioneer of behaviorism. He proposed making general psychology a scientific discipline by using experimental laboratory methods to set exploitable results that can then be statistically evaluated [37]. Works of the physiologist Ivan Pavlov on the conditioning of animals influenced Watson. This leads him to admit that all behavior operates on a principle of "stimulus-response" or what is called "classical conditioning".

For the advocates of behaviorism (such as Pavlov and Skinner), the learning process is perceived in a very simplistic way as an external change in human behavior which results from specific instrumental conditioning. This means that the confrontation of any individual with a discriminative stimulus inevitably leads usually to the emergence of constructed responses over time. To teach a certain skill, the behaviorist approach proposes to break it down into sub-objectives which have to be simultaneously assimilated and mastered. In this perspective, the teacher should be able to present information to learners under restricted stimulus associated with reinforcement. The learners' role here is to respond to these stimuli by adopting the expected behavior. The teacher also proposes progressive practical exercises that allow checking the acquisition of knowledge while giving positive and/or negative feedback based on the responses provided. The type of pedagogical scenario that prevails, in that case, is the one which highlights learning by reception-exercises-test (see Figure 1). 


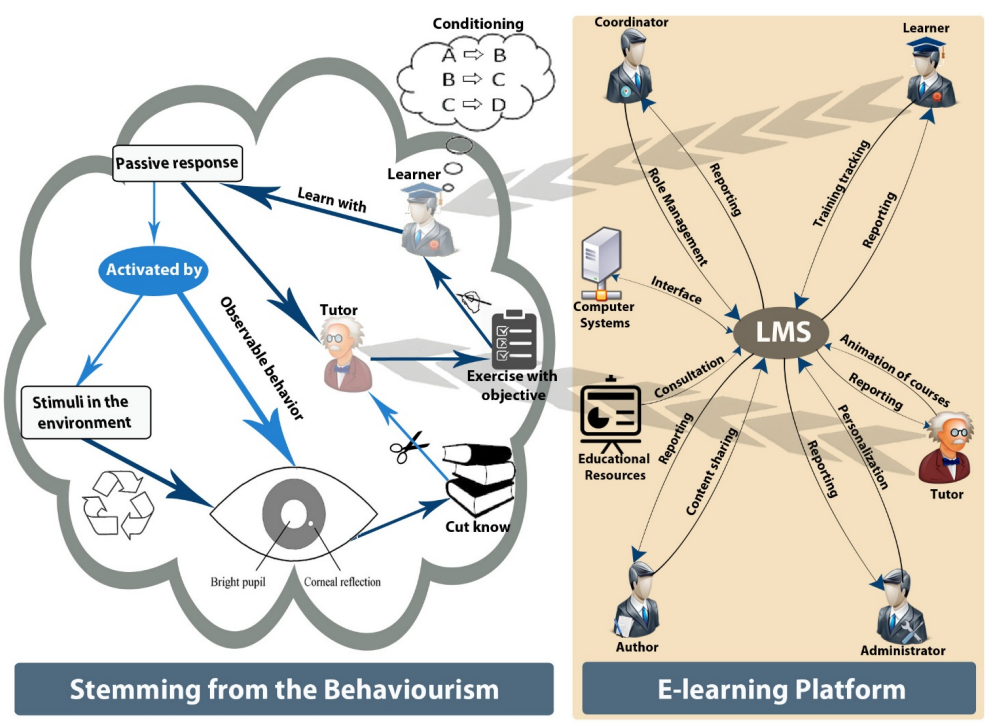

Fig. 1. LMS and underlying behaviorism model

The mark of behaviorism can be found in the LMS which displays systematic exercises allowing learning by repetition (trial and error) and in which the principles of conditioning are integrated.

\subsection{Self-management space and the cognitivist}

Cognitivism is born at the same time as Artificial Intelligence, in 1956. Miller and Bruner propose it in reaction to Behaviorism. It focuses on ways of thinking and solving problems. Learning cannot be limited to a conditioned recording, but should rather be considered as requiring complex processing of the received information. Memory has its structure, which involves the organization of information and the use of strategies to manage this organization [38].

Cognitive psychology considers that there are three broad categories of knowledge: declarative, procedural, and conditional knowledge. It invites the teacher to develop different strategies to facilitate the integration of each of them because they are represented differently in memory; the declarative knowledge answers the WHAT, the procedural knowledge points to the HOW, and the conditional knowledge to the WHEN and the WHY [42].

There are different categories of cognitive strategies that contain several types of strategies. Furthermore, cognitive and metacognitive strategies can be the subject of systematic teaching. Besides, the authors [41, 40] insist that the teaching of these strategies be carried out in the learning context, in the program course. The teaching of these strategies will be effective if these strategies are integrated with the ordinary curricula, and presented to learners as a necessary means to the achievement of the learning objectives. However, quality education is not limited to telling learners what to do; it consists also of showing how to learn. Tardif [39] presents a learning model 
based on the importance of the gradual and effective appropriation of cognitive and metacognitive strategies. This model has the aim to stimulate cognitive and emotional engagement, to show the learner how to treat the information adequately, and to bring the learner to make transfers.

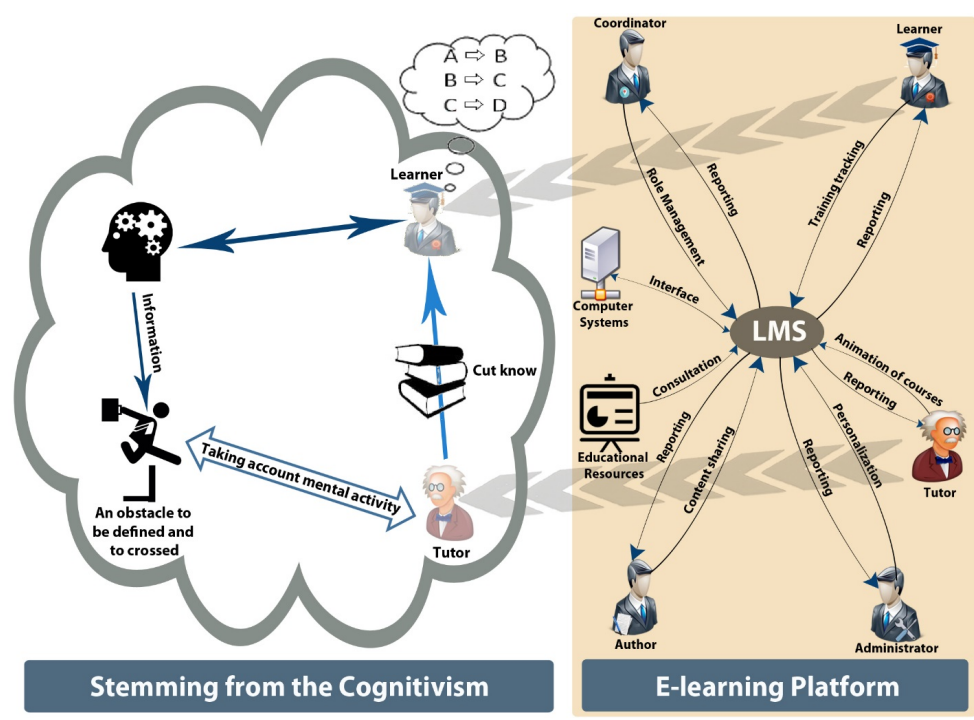

Fig. 2. LMS and underlying cognitivist model

For an LMS based on the cognitivist approach, the learner is an active informationprocessing system, similar to a computer: it perceives information that comes from the outside world, recognizes it, stores it in memory, then recovers it from his/her memory when he/she needs it to understand his/her environment or resolve problems [34]. The teacher is the manager of learning. He/she guides, animates, directs, advises, explains, regulates, and remedies. Knowledge becomes an external reality that the learner must integrate into his/her mental patterns and reuse rather than acquire observable behaviors [43]. Besides, the favored teaching method leaves room for multiple learning pathways to take into account the different individual variables that can influence how learners process information. The cognitivist teacher will be invited to use ICTs that promote high interactivity with learners, such as simulators, experiments, and intelligent tutorials. However, the cognitivist model has an important limit, related to the fact that a well-structured material is not sufficient to ensure learning. The motivation of the learners is a determining factor because it provides the required energy to perform learnings (see Figure 2).

\subsection{Self-management space and the social constructivist}

Social constructivism is the fruit of the development of learning theories under the influence of some researchers, particularly Lev Vygotski in 1934 [21, 11], who wanted to depart from behaviorism by integrating other factors that can positively 
influence knowledge acquisition. Thus, new ideas emerged in connection with the possible interaction of individuals with the environment.

Social constructivism outlines learning by construction in a community of learners. In this light, learners are expected to interact with the available human resources (teachers, tutors, other learners, etc.) in the proposed learning environment. In this way, the learners' psychological functions increase through social cognitive conflicts that occur between them. These conflicts lead to the development of the zone of proximal development ${ }^{3}[10]$ and thus facilitate the acquisition of knowledge.

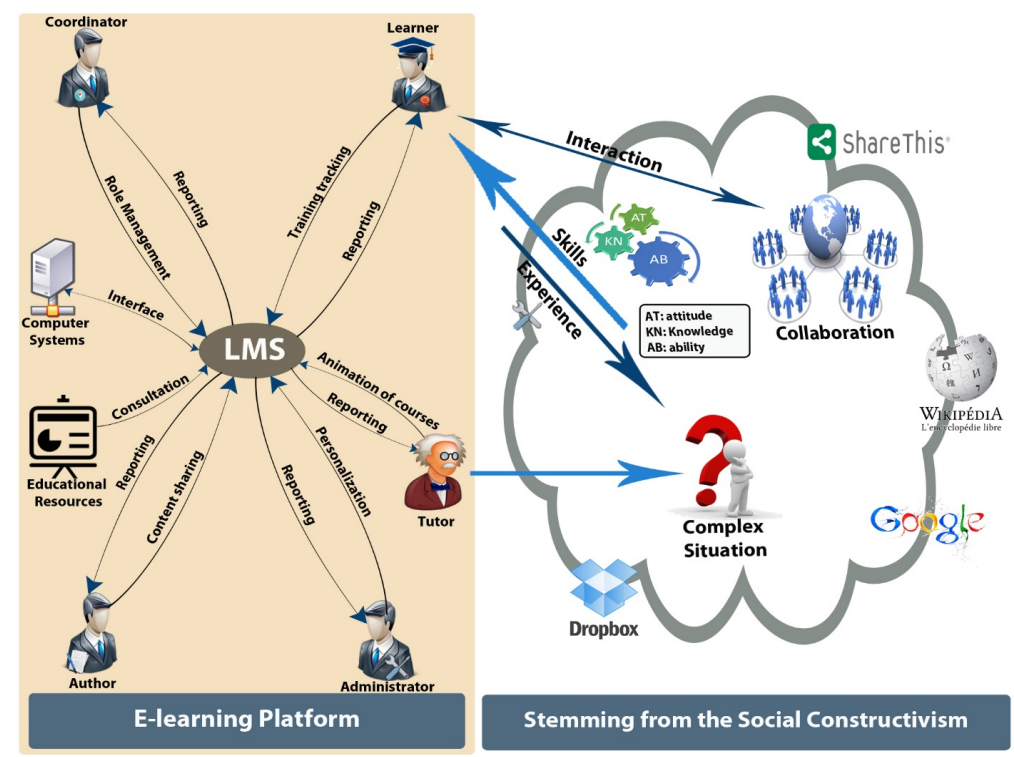

Fig. 3. LMS and underlying social constructivism model

Learning is seen as the process of acquisition of knowledge through the exchange between teachers and learners or between learners. These latter learn not only through the transmission of knowledge by their teacher but also through interactions [9]. According to this model, learning is a matter of the development of the zone of proximal development: this zone includes the tasks that learners can achieve under the guidance of an adult; they are not very tough or so easy. The development of this zone is a sign that the learners' level of potential development increases efficiently [28].

The teacher's role is to define precisely this zone to design suitable exercises for learners. Furthermore, designing collaborative tasks, which involve discussions and exchange (socio-cognitive conflicts) between learners is so important in this model. Errors are considered as a point of support for the construction of new knowledge.

Based on the social constructivism approach (see Figure 3), the design of the LMS was oriented towards integrating online communication and collaboration tools. In

3 "The distance between actual development level as determined by independent problem solving and the level of potential development as determined through problem solving under adult guidance or in collaboration with more capable peers (Vygotsky, 1978, p. 86)". 
practice, a wide range of platforms, particularly the social constructivist ones, proposes a set of tools, which allows sharing, exchanging, and interacting in a synchronous and asynchronous mode such as blogs, wikis, forums, etc.

In summary, the ideas of social constructivist authors have highlighted the social nature of learning. Other authors have taken one step further by emphasizing the distribution of intelligence between individuals and the environment. Furthermore, considering that learning occurs in a social context is no longer enough to ensure deep learning. Indeed, working in groups can negatively affect the quality of learning if the following conditions are not taken into consideration: learning styles, the way groups are formed, interaction modality, and the characteristics of tasks.

\section{Concepts}

\subsection{Instructional management systems - Learning design}

IMS-LD was published in 2003 by the IMS/GLC ${ }^{4}$. The source $\left(\mathrm{EML}^{5}\right)$ of the proposed language was assessed by the European Committee for Standardization (CEN) in a comparative study of different SRMS [5, 7]. EML is defined by CEN / ISS as "an information aggregation and semantic model describing the content and processes involved in a unit of learning from an educational perspective and to ensure the reusability and interoperability." [23]. In this context, the North American IMS consortium undertook a study and provided a specification of such a language, giving birth in February 2003 to the Learning Design specification V1.0 (IMS-LD). She adds that the proposal, largely inspired by EML developed by $[6,7]$ (OUNL), provides a conceptual framework for modeling a Learning Unit and claims to offer a good compromise between the generic implementation of a variety of instructional approaches and the power of expression that allows an accurate description of each learning unit.

\subsection{Atlas Language Transformation (ATL)}

In their operational ATL, Canals [27] states that to deal with the transformation of models, it is difficult and cumbersome to use object languages since we spend so much effort on the development of transformation definitions of Framework for the set work. The use of XSLT as a language if it is more direct and adapted by the rest are difficult to maintain [27]. We follow their choice by focusing on the implementation of approaches centered on the MDA (Model Driven Architecture), MDE (Model Driven Engineering), and QVT (Queries View Transformation) tools. Query / View / Transformation (QVT) [12] is a standard defined by the OMG. This is a standardized language to express model transformations. QVT is not advanced sufficiently now in its definition for Queries and View aspects. Against

${ }^{4}$ IMS/GLC: Instructional Management Systems Global Learning Consortium

${ }^{5}$ EML: Educational Modelling Language. 
transformation by the appearance expressed by the MDA, the approach has resulted in various experiments (e.g., Triskell, ATL) on both academic and commercial levels. To determine the transformation, it is necessary to have tools of transformations. These are based on languages transformations must respect the QVT standard [12], proposed by the OMG [25]. There is an offer of free tools (ATL, MTF, MTL, QVTP, etc.) and commercial (e.g., MIA). We chose ATL (Atlas Transformation Language) from the provision of free tools to the extent that only ATL has a spirit consistent with $\mathrm{OMG} / \mathrm{MDA} / \mathrm{MOF} / \mathrm{QVT}[27]$.

\section{Generate an IMS-LD Meta-Model of Self-Management Space}

\subsection{Correspondence between the IMS-LD and the self-management meta- model}

In this research, we try to adapt the model IMS-LD with a self-management metamodel supporting LMS. This adaptation will go through three stages, first the development of an LMS self-management meta-model. Secondly, the study of the correspondence between the developed meta-model. Finally, the IMS-LD model and their transformation to the IMS-LD meta-model reduced the MDA approach in a transformation that is based on the rules implemented in the ATL language. However, we will talk about the IT design of our LMS self-management meta-model without using the transformation that is based on the rules implemented in the ATL language, because we have detected the same problems in several works [10, 20, 23, 26, 29, 32, $33,44,8,4]$. In IMS-LD, we do not have the opportunity to build a course which consists of several chapters. For this, there is at this level a semantic loss.

Table 1. Correspondence between the IMS-LD and the self-management meta-model

\begin{tabular}{|l|l|}
\hline \multicolumn{1}{|c|}{ Self-management meta-model } & \multicolumn{1}{c|}{ IMS-LD } \\
\hline Prerequisite & Prerequisite \\
\hline The role, and features & Role \\
\hline Member & Person \\
\hline Coordinator, teacher, and tutor & Staff \\
\hline Learner & Learner \\
\hline Objective & Learning Objective \\
\hline Course and chapter & Learning Object \\
\hline Tools & Services \\
\hline Espace de production & Environment \\
\hline
\end{tabular}

Consequently, the majority of classes designed in our LMS self-management metamodel corresponds perfectly with the IMS-LD model, which makes possible their transformation to it. The transformation of the model is a technique that aims to put links between models to avoid unnecessary reproductions. In Table 1, we have tried to collect all the classes of the LMS self-management meta-model and their equivalent at the IMS-LD. 


\subsection{Self-management meta-model compatible with IMS-LD}

In our research, we propose a meta-model for a self-management space designed to achieve the needs of the LMS and the needs of teachers and learners. Therefore, we establish the following diagram (see Figure 5) as the first proposal of a selfmanagement meta-model for LMS.

Indeed, we will talk about the IT design of our self-management meta-model for LMS. This led us to develop our meta-model in which we will eventually identify the features of the constituent entities of our meta-model in which we specify the different classes of our modeling.



Fig. 4. The conceptual meta-model of the self-management space

Teachers and tutors can create self-management through the following technological advances:

- Test managing. Teachers or tutors can create tests with multiple-choice, multiple answers, true/false, Likert, ordering, matching, drag and drop, and several openended question types. M/C, M/A, ordering, matching, and $\mathrm{T} / \mathrm{F}$ questions are marked automatically. Moreover, these tests enable learners to add questions to a Question Bank, then select questions from it to assemble a test or quiz.

- Course managing. Courses on a system can be sorted, their authors modified, and their teachers or tutors managed. We can create new courses and assign them to teachers or tutors. Besides, we can use course backups to generate initial content for a new course.

- Group managing. Teachers or tutors can manually create or automatically generate workgroups for a variety of purposes. Groups might be used to provide a private area where learners can work.

- Backup managing. The entire content and structure of a course can be backed up and stored on the LMS server, or downloaded and saved to your local computer for safe-keeping. 
- File managing. Teachers, tutors, or learners can upload and manage course-related files. Directories can be created to sort files; zip archives can be uploaded and unpacked. A popup file manager can be opened alongside the Content Editor or test question editors.

- Module managing. Administrators or coordinators can install modules, enable and disable them, and define a default set of modules and menu blocks for new courses.

- Themes managing. Easily create a custom version of LMS by modifying an existing theme or creating a new one. Assign themes to categories of courses to give all related courses the same look.

- User managing. Users on a system can be sorted, personal information can be viewed, and access privileges can be modified. User accounts can be managed by adding, modifying, or deleting accounts.

\section{Designing an IMS-LD Model of Self-Management Space}

In our work, we will try to design e-learning models, so we have to create a use case diagram and class diagram model based on the theoretical study of our current work and will simultaneously ensure its projections to the models. In addition to that, we will try to recognize our models with the IMS-LD model. This compatibility will not be a direct way c to d, the same IMS-LD terminology will be used for all classes of our proposed self-management model; there is an equivalent class in the IMS-LD meta-model of the self-management space, proposed in Figure 6, which will greatly help us in the design level.

\subsection{Use case diagram}

The use case diagrams identify the functionality provided by the model (use case); users interact with the system (actors), and the interactions between them. The main objectives of the use case diagrams are to:

- Provide a high-level view of the model.

- Identify users ("actors") of the model.

- Define the roles of the actors in the model.

Table 2 describes the service function for each actor.

Here is the use case diagram (see Figure 6) of the model representing the external actors who will interact with the system and how they will use it.

\subsection{Class diagram IMS-LD}

In our paper, we propose a class diagram IMS-LD model for the self-management space (see Figure 7) from our meta-model proposed in Figure 6. In this last one, we defined the properties of each class and the relations between them. The majority of 
the classes designed in our class diagram model corresponds perfectly to the metamodel proposed in Figure 6, which makes possible their transformations. Model transformation is a technique for linking patterns to avoid unnecessary duplication.



Fig. 5. Use case diagram of self-management space

Table 2. Function description

\begin{tabular}{|l|l|l|}
\hline \multicolumn{1}{|c|}{ Actor } & \multicolumn{1}{|c|}{ Function } & \multicolumn{1}{c|}{ Description } \\
\hline \multirow{4}{*}{ Learner } & Set language & The learner can define the language of these studies \\
\cline { 2 - 3 } & Set theme & The learner can define the theme of his office \\
\cline { 2 - 3 } & View documents & Learners can view documents \\
\cline { 2 - 3 } & Upload documents & The learner can upload documents \\
\hline \multirow{5}{*}{ Tutor } & Manage courses & The tutor can add, modify or delete courses \\
\cline { 2 - 3 } & Manage groups & The tutor can add, modify or delete groups \\
\cline { 2 - 3 } & Assign learners to groups & The tutor can assign learners to groups \\
\cline { 2 - 3 } & Set language & $\begin{array}{l}\text { The tutor can define the language of study for their } \\
\text { learners }\end{array}$ \\
\cline { 2 - 3 } & Set theme & $\begin{array}{l}\text { The tutor can define the theme of the personal offices } \\
\text { of these learners }\end{array}$ \\
\hline \multirow{5}{*}{ Teacher } & Create Quizzes & The teacher can create Quizzes \\
\cline { 2 - 3 } & Create activities & The teacher can create activities \\
\cline { 2 - 3 } & Create projects & The teacher can create projects \\
\cline { 2 - 3 } & Create assessments & The teacher can create assessments \\
\cline { 2 - 3 } & Set prerequisites & The teacher can set prerequisites for course \\
\cline { 2 - 3 } & Set objectives & $\begin{array}{l}\text { The teacher can set objectives for course, projects, } \\
\text { activities, quizzes, and assessments }\end{array}$ \\
\cline { 2 - 2 } & & \\
\hline
\end{tabular}




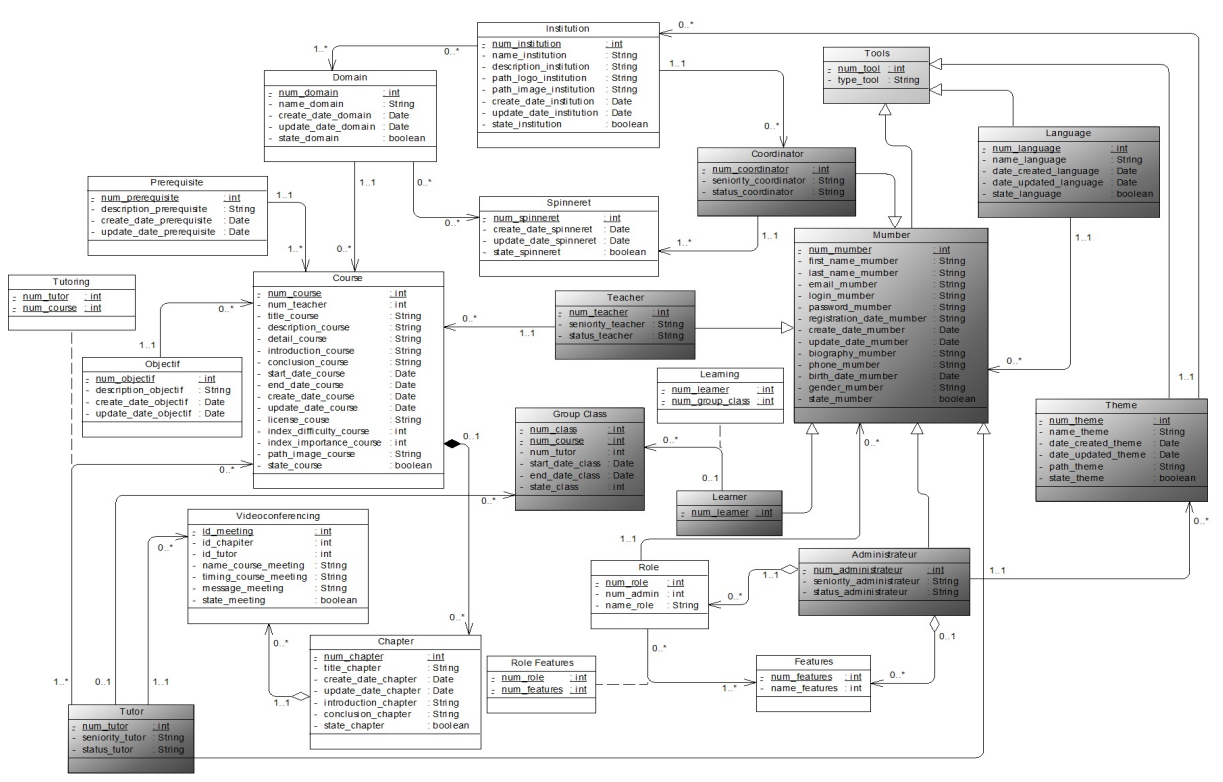

Fig. 6. Class Diagram of self-management space

\section{Conclusion and Perspectives}

We are on the way to the design and modeling of the self-management model of a new Learning Management System compatible with IMS-LD. This conception is based on active teachings learner-centered, from which we opted for four learning theories as to the teaching and learning base of this new LMS, namely traditional pedagogy, behaviorism, cognitivism, and social constructivism.

To achieve our goal, we need to reach the model validation step, which is one of the tasks to be performed in our future work; also, we seek a framework that will guide us better to start the development part.

\section{$8 \quad$ References}

[1] M. Ouadoud, M. Y. Chkouri, A. Nejjari, K. E. EL Kadiri, (2016) Studying and Analyzing the Evaluation Dimensions of E-learning Platforms Relying on a Software Engineering Approach. International Journal of Emerging Technologies in Learning (iJET). 2016, Vol. 11 Issue 1, p11-20. 10p. http://dx.doi.org/10.3991/ijet.v11i01.4924

[2] M. Ouadoud, M. Y. Chkouri, A. Nejjari, and K. E. E. Kadiri, "Studying and comparing the free e-learning platforms," in 2016 4th IEEE International Colloquium on Information Science and Technology (CiSt), 2016, pp. 581-586. http://dx.doi.org/10.1109 CIST.2016.7804953

[3] M. Ouadoud, M. Y. Chkouri, A. Nejjari, and K. E. El Kadiri, "Exploring a Recommendation System of Free E-learning Platforms: Functional Architecture of the 
System," International Journal of Emerging Technologies in Learning (iJET), vol. 12, no 02, p. 219-226, Feb. 2017. https://dx.doi.org/10.3991/ijet.v12i02.6381

[4] M. Ouadoud and M. Y. Chkouri, "Generate a Meta-Model Content for Sharing Space of Learning Management System Compatible with IMS-LD," in Innovations in Smart Cities Applications Edition 2, 2019, pp. 348-363. https://doi.org/10.1007/978-3-030-11196-0_31

[5] CEN/ISS WS/LT, Learning Technologies Workshop "Survey of Educational Modelling Languages (EMLs)".Version 1, September 2002.

[6] R. Koper, (2001). Modeling Units of Study from a Pedagogical Perspective, the pedagogical meta-model behind EML.

[7] D. Burgos, M. Arnaud, P. Neuhauser, and R. Koper, "IMS Learning Design: la flexibilité pédagogique au service des besoins de l'e-formation," Association EPI, Décembre-2005. https://www.epi.asso.fr/revue/articles/a0512c.htm

[8] M. Ouadoud and M. Y. Chkouri, "Designing an IMS-LD Model for Sharing Space of Learning Management System," in Innovations in Smart Cities Applications Edition 2, 2019, pp. 334-347. https://doi.org/10.1007/978-3-030-11196-0_30

[9] W. Doise and G. Mugny, Le développement social de l'intelligence (Vol. 1). Paris : Interéditions, 1981.

[10] M. Ouadoud, N. Rida, and M. Y. Chkouri, "Designing an IMS-LD Model for Collaboration Space of Learning Management System," in 2018 IEEE 5th International Congress on Information Science and Technology (CiSt), 2018, pp. 380-385. https://doi.org/10.1109 CIST.2018.8596588

[11] A. El Mhouti, A. Nasseh, and M. Erradi, "Les TIC au service d'un enseignementapprentissage socioconstructiviste," Association EPI, janv-2013. https://www.epi.asso.fr /revue/articles/a1301g.htm

[12] OMG/RFP/QVT MOF 2.0 Query/Views/Transformations RFP. OMG, Object Management Group, 28 Oct. 2002.

[13] M. Sadiq and M. Talbi, "Modélisation des unités d'apprentissage sur des plates-formes de formation à distance," Association EPI, Mar-2010. https://www.epi.asso.fr $\underline{\text { revue/articles/a1003e.htm }}$

[14] E. Tonye, "Modeling a framework for open and distance learning in sub-Saharan African countries," frantice.net, numéro 2, December 2010.

[15] K. Chouchane, "Modélisation et réalisation d'une approche pour le m-learning," Magister en Informatique Option Système d'Informatique et de Communication (SIC) 2012, Université Hadj Lakhdar - Batna - Algérienne.

[16] S. Brunel, P. Girard, and M. Lamago, "Des plateformes pour enseigner à distance: vers une modélisation générale de leurs fonctions," in AIP Primeca 2015, La Plagne, France, 2015.

[17] B. née Dahmani Farida, "Modélisation basée ontologies pour l'apprentissage interactif Application à l'évaluation des connaissances de l'apprenant," $\mathrm{PhD}$ dissertation in computer science, Computer Science Department, Mouloud Mammeri University of Tizi-Ouzou, Algeria, 28 November, 2010.

[18] Alfanet project "CopperCore V 3.3," Nov-2008. CopperCore is one of the OUNL's contributions to the Alfanet project

[19] Bolton, "RELOAD Project: Editor," United Kingdom: The University of Bolton, The University of Strathclyde and JISC, 2005.

[20] F. El-Moudden, S. Aammou, and M. Khaldi. "A Tool to Generate a Collaborative Content Compatible with IMS-LD," International Journal of Software and Web Sciences, 11(1), December 2014-February 2015, pp. 01-08. 
[21] M. Chekour, M. Laafou, and R. Janati-Idrissi, "L'évolution des théories de l'apprentissage à l'ère du numérique," Association EPI, févr-2015. https://www.epi.asso.fr /revue/articles/a1502b.htm

[22] M. Ouadoud, M. Y. Chkouri, and A. Nejjari, "LeaderTICE: A Platforms Recommendation System Based on a Comparative and Evaluative Study of Free E-learning Platforms," International Journal of Online Engineering (iJOE), vol. 14, no. 01, pp. 132-161, Jan. 2018. https://doi.org/10.3991/ijoe.v14i01.7865

[23] F. El-Moudden, M. Khaldi, and S. Aammou, "Designing an IMS-LD Model for Collaborative Learning," IJACSA, vol. 1, no. 6, pp. 42-48.

[24] M. Ouadoud, A. Nejjari, M. Y. Chkouri, and K. E. E. Kadiri, "Educational modeling of a learning management system," in 2017 International Conference on Electrical and Information Technologies (ICEIT), 2017, pp. 1-6. http://dx.doi.org/10.1109 /EITech.2017.8255247

[25] J. Bézivin, G. Dupé, F. Jouault, G. Pitette, and J. Eddine Rougui. First experiments with the atl model transformation language: Transforming xslt into xquery. In OOPSLA 2003 Workshop, Anaheim, California, 2003.

[26] M. Ouadoud and M. Y. Chkouri, "Designing an IMS-LD Model for Communication Space of Learning Management System," in Advanced Intelligent Systems for Sustainable Development (AI2SD’2018), 2019, pp. 40-54. https://doi.org/10.1007/978-3-030-11928$\underline{74}$

[27] A. Canals, C. Le Camus, M. Feau, G. Jolly, V. Bonnafous, and P. Bazavan, "Une utilisation opérationnelle d'ATL: L'intégration de la transformation de modèles dans le projet TOPCASED," in Génie logiciel, 2005, pp. 21-26.

[28] L. S. Vygotsky, Mind in Society: The Development of Higher Psychological Processes, Revised ed. edition. Cambridge: Harvard University Press, 1978.

[29] M. Ouadoud and M. Y. Chkouri, "Generate a Meta-Model Content for Communication Space of Learning Management System Compatible with IMS-LD," in Advanced Intelligent Systems for Sustainable Development (AI2SD’2018), 2019, pp. 24-39. https://doi.org/10.1007/978-3-030-11928-7 3

[30] M. Ouadoud, M. Y. Chkouri, and A. Nejjari, "Learning Management System and the Underlying Learning Theories: Towards a new Modeling of an LMS," International Journal of Information Science and Technology (iJIST), vol. 2, no. 1, pp. 25-33, Mar. 2018.

[31] M. Ouadoud, A. Nejjari, M. Y. Chkouri, and K. E. El-Kadiri, "Learning Management System and the Underlying Learning Theories," in Innovations in Smart Cities and Applications, 2017, pp. 732-744. https://doi.org/10.1007/978-3-319-74500-8 67

[32] M. Ouadoud and M. Y. Chkouri, "Generate a Meta-Model Content for Disciplinary Information Space of Learning Management System Compatible with IMS-LD," in Proceedings of the 3rd International Conference on Smart City Applications, New York, NY, USA, 2018, p. 39:1-39:8. http://dx.doi.org/10.1145/3286606.3286816

[33] M. Ouadoud, T. Chafiq, and M. Y. Chkouri, "Designing an IMS-LD Model for Disciplinary Information Space of Learning Management System," in Proceedings of the 3rd International Conference on Smart City Applications, New York, NY, USA, 2018, p. 40:1-40:9. http://dx.doi.org/10.1145/3286606.3286817

[34] R. Bibeau, "École informatisée clés en main. Projet franco-québécois de recherche-action," Revue de l'EPI (Enseignement Public et Informatique), no. 82, pp. 137-147, Jun. 1996.

[35] F. Morandi, Introduction à la pédagogie. Armand Colin, 2006.

[36] T. L. Good and J. E. Brophy, Educational Psychology: A Realistic Approach, 4e éd., New York : Longman, 1995.

[37] J. Watson, Le béhaviorisme. Paris. Editions Cepi, 1972. 
[38] S. Crozat, (2002). Éléments pour la conception industrialisée des supports pédagogiques numériques (Doctoral dissertation, Université de Technologie de Compiègne).

[39] J. Tardif, (1992). Pour un enseignement stratégique. L'apport de la psychologie cognitive. Montréal, Québec: Logiques. https://doi.org/10.7202/031636ar

[40] C. Weinstein, and R. Mayer, (1986). The teaching of learning strategies, dans M. C. Wittrock (dir.), Handbook of Research on Teaching, 3e éd., New York: Macmillan.

[41] M. Pressley, and K. Harris, (1990). What we really know about strategy instruction. Educational leadership, 48(1), 31-35.

[42] M. Chekour, M. Laafou, et R. Janati-Idrissi, « L'évolution des théories de l'apprentissage à l'ère du numérique », Revue de l'EPI (Enseignement Public et Informatique), feb-2015. https://www.epi.asso.fr/revue/articles/a1502b.htm

[43] R. Bibeau, (2007). Les technologies de l'information et de la communication peuvent contribuer à améliorer les résultats scolaires des élèves. Revue de l'EPI, (94). https://www.epi.asso.fr/revue/articles/a0704b.htm

[44] M. Ouadoud, T. Chafiq, N. Rida, and M. Y. Chkouri, "Generate a Meta-Model Content for Collaboration Space of Learning Management System Compatible with IMS-LD," International Journal of Interactive Mobile Technologies (iJIM), vol. 13, no. 1, pp. 37-52, Jan. 2019. https://doi.org/10.3991/ijim.v13i01.9440

\section{Authors}

Mohammed Ouadoud is a Muslim man from Morocco. He is a Ph.D. Research Scholar in Computer sciences, at the Laboratory of the Information System and Software Engineering (SIGL) at National School of Applied Sciences, Abdelmalek Essaâdi University. In 2018, he completed his Ph.D. thesis in computer science at the Faculty of Science of Tetouan, Morocco. His dissertation research focuses on Modeling and Prototyping a Learning Management System Based on the IMD-LD, the NoSQL, and the Hybridization between Learning Theories. He has a Master's degree in Instructional design multimedia engineering from the École Normale Supérieure of Martil, Morocco in 2013. His current research focuses on E-learning, Software Engineering, Geomatics, and Bigdata. $\mathrm{He}$ is a reviewer in several international journals. (E-mail: mohammed.ouadoud@gmail.com).

Nouha Rida is currently a Ph.D. student at Computer and Education Research Laboratory at Mohammadia School of Engineer, Mohammed V University, Morocco. She received her degree in engineering in computer science from "Ecole Nationale Superieur de Mine of Rabat". Her main research interests are related to the intelligent transportation system and road traffic optimization.

Tarik Chafiq is a part-time lecturer and scientific collaborator at Hassan II University who is specialized in the research field of geomatics such as Geographical Information Systems (GIS) analyses and Spatial Data Infrastructures (SDI). From 2016 and 2017, he had been a research scientist at Alexandru Ioan Cuza. He got his $\mathrm{Ph} . \mathrm{D}$. degree and Master's degree in geoinformatics. Furthermore, Microsoft certifies him as an expert in C \#and HTML5.

Article submitted 2020-05-01. Resubmitted 2020-10-29. Final acceptance 2020-11-03. Final version published as submitted by the authors. 